\title{
A CRISE DO ESTADO E DO DIREITO NA MODERNIDADE E PERSPECTIVAS PÓS-MODERNAS
}

\author{
Antônio Carlos Diniz Murta1 \\ Priscila Ramos Netto Viana2
}

\section{RESUMO:}

Este artigo objetiva traçar um panorama do Estado e do direito na modernidade e as suas transformações ao longo desse período, até a culminação de sua crise. Analisar-se-á as razões que levaram a essa crise e quais as perspectivas que se mostram para o Estado e o direito em uma sociedade pós-moderna. Para alcançar o objetivo proposto, utilizar-se-á de fontes predominantemente teóricas, em uma abordagem compreensivo-exploratória e críticoreflexiva sobre a matéria.

Palavras-Chave: Modernidade; Estado Liberal; Estado-Providência; Direito; PósModernidade.

\section{THE CRISIS OF STATE AND LAW IN MODERNITY AND POSTMODERN PERSPECTIVES}

\begin{abstract}
:
This article aims to draw a picture of the State an law in modernity and its transformations over this period, until the culmination of its crisis. It will analyze the reasons that led to this crisis and what perspectives are shown for the State and law in a postmodern society. To achieve the proposed objective will be used, predominantly theoretical sources, in a comprehensive-exploratory and critical-reflexive approach on the matter.
\end{abstract}

Keywords: Modernity; Liberal State; Welfare State; Law; Postmodernity.

\section{INTRODUÇÃO}

A era moderna inaugurou o primado da razão e prometeu trazer para a humanidade o conhecimento e a liberdade individual obscurecidos durante a Idade Média. $\mathrm{O}$ Estado Moderno surgido com o fim do absolutismo é garantia dessa liberdade e condição para o seu exercício, estabelecendo uma ordem jurídica pautada pela positivação dos direitos individuais, regulando minimamente as relações privadas entre as pessoas, estabelecendo a igualdade formal entre elas e limitando a sua própria atuação.

1 Doutor em Direito pela UFMG. Professor titular da Universidade FUMEC

2 Mestranda em Direito Pela Faculadade de Ciências Humanas, Sociais e da Saúde/FHC da Universidade FUMEC 
O direito moderno molda-se por sua produção exclusivamente estatal, reduzido às leis ditadas pelo Estado Liberal. Ao ser estudado sob a perspectiva da racionalidade das ciências naturais, reduz-se ao seu matiz dogmático, por força do positivismo jurídico. Nesse contexto, a lei é a camisa de força do jurista, moldando o seu modo de enxergar a sociedade e garantindo a certeza e a segurança jurídica, princípio e fim de toda ideia de direito.

Contudo, tal modelo mostra-se insuficiente para garantir os ideais de liberdade e igualdade, fazendo com que o Estado Moderno se reivente para tentar o cumprimento das promessas trazidas pela modernidade, na busca da promoção da justiça social, sem prejuízo da manutenção da lógica de mercado capitalista.

O Estado torna-se, assim, provedor, ampliando a sua esfera de atuação, por meio da positivação de direitos sociais, da implementação de políticas sociais distributivas e da inserção do Estado em questões antes afetas apenas aos interesses particulares, como a intervenção na economia. O direito, enquanto produto da ordem estatal, acompanha essa transformação e reveste-se de um caráter material e regulador, sem contudo, abrir mão de sua positividade.

O crescimento da figura estatal e a proliferação dos instrumentos legais, todavia, não conseguem assegurar uma distribuição mais justa dos benefícios sociais e um sistema politico estável e democrático, denunciando, assim, a inexecução das promessas da modernidade e a falência do positivismo jurídico e dos diversos modelos estatais.

A crise da modernidade, reclama, assim o abandono do seus paradigmas e a busca por uma revisão dos pressupostos de legitimidade do Estado e do direito, a partir da constatação de que a racionalidade prática não tem as respostas para os problemas que se observa na nova dinâmica de uma sociedade pós-moderna.

Este artigo objetiva traçar um panorama do Estado e do direito na modernidade e as suas transformações ao longo desse período, até a culminação de sua crise. Analisar-se-á as razões que levaram a essa crise e quais as perspectivas que se desenham para o Estado e o direito em uma sociedade pós-moderna. Para alcançar o objetivo proposto, utilizar-se-á de fontes predominantemente teóricas, em uma abordagem compreensivo-exploratória e críticoreflexiva sobre a matéria.

\section{CARACTERIZAÇÃO DA MODERNIDADE}


Quando se utiliza a expressão "modernidade" é preciso delimitar o seu alcance e o seu contexto, para que não se corra o risco de desenvolver um texto com base apenas no senso comum $^{3}$, desprovido da racionalidade crítica inerente às produções decorrentes do saber científico.

Modernidade aqui não será empregada para se referir à Idade Moderna (1453-1789), mas sim para delimitar um período da história ocidental da humanidade caracterizado pela conjunção de diversos elementos (o desenvolvimento científico e técnico, a concentração dos meios de produção e o surgimento da figura do Estado) que nas palavras de Jacques Chevallier (2009, p.14), "traduzem um processo de "racionalização" de organização das sociedades, sob todos os aspectos ${ }^{4}$."

A modernidade surge a partir do século XVII, após o Renascimento, sob os anseios da racionalidade, da liberdade, do conhecimento, da primazia do indivíduo e da ideia de progresso, buscando superar as "trevas" e o domínio religioso imanentes ao período medieval e trazendo uma nova visão da sociedade, do homem, da natureza, do mundo.

De acordo com CHEVALLIER (2009), as transformações da modernidade pautaram-se em dois polos essenciais: o culto da razão, que libera o homem do jugo da natureza e dos deuses, tornando-o senhor de si e do seu destino; e o primado do indivíduo, referência suprema da organização social e política.

Ao discorrer sobre o culto da razão, CHEVALLIER (2009, p. 14) destaca os mitos criados sob essa perspectiva, a saber:

crença nas virtudes da "Ciência", dotando o homem de um senhorio cada vez maior sobre a Natureza; fé no "Progresso", que deve se traduzir em uma melhoria do bem-

\footnotetext{
3 Nos dizeres de Eduardo C. B. Bittar et al., o senso comum "corresponde a um conjunto assistemático de conhecimentos de diversas naturezas, que corresponde à multiplicidade das informações recebidas e colhidas ao longo de determinado tempo de experiência humana." (BITTAR, Eduardo C. B.; ALMEIDA, Guilherme Assis de. Curso de Filosofia do Direito. 11a ed. São Paulo, Atlas, 2015, p 37.)

4 Para Michel Foucault, a modernidade não seria um dado período na história da humanidade, mas sim uma atitude, assim entendida como "uma maneira de pensar e sentir, uma maneira também de agir e de se conduzir que, tudo ao mesmo tempo, marca uma pertinência e se apresenta como uma tarefa". (FOUCAULT, Michel. Ditos e escritos II: arqueologia das ciências e história dos sistemas de pensamento. Rio de Janeiro: Forense Universitária 2000, p. 341.) Eduardo C. B. Bittar adverte com maestria que a modernidade, embora não possa ser deslocada do tempo e do espaço, não se atrela somente a esses elementos: "Deve também ser compreendida como um conjunto de transformações culturais, sociais e econômicas, bem como políticas, que haveriam de se produzir, sustentadas por fortes ideais filosóficos, entre os séculos XVII e XIX, com vistas à consolidação de características [...] tornadas projeto-meta para a reconfiguração das relações humanas e sociais na Europa Ocidental, algo que acabou por se universalizar." (BITTAR, Carlos C. B. O Direito na Pós-Modernidade. 3a ed. São Paulo: Atlas, 2014.)
} 
estar individual e da justiça social; ideia de que a "História" tem um sentido (historicismo) e que a Razão acabará por impor sua lei; convicção no "Universalismo" dos modelos construídos no Ocidente, chamados a servir, enquanto expressão própria da Razão, de modelos de referência.

As relações sociais na modernidade, construídas sob os auspícios da centralidade do indivíduo, por sua vez, implicam na percepção de singularidade de cada ser humano, de sua autonomia e liberdade de fazer o que bem entende, "mas é também a ideia de que a fonte de todo o poder, o fundamento de toda a autoridade reside no consentimento dos indivíduos. $\mathrm{O}$ indivíduo torna-se assim a referência suprema, tanto na esfera particular como na esfera pública, através da figura do cidadão" (CHEVALLIER, 2009, p. 14).

A perspectiva da modernidade apresentada por CHEVALLIER torna-se mais densa ao exame do pensamento de Boaventura de Sousa Santos (2005), que concebe a modernidade enquanto projeto sócio-cultural, erigida com base em dois pilares, o da regulação e o da emancipação.

O pilar da regulação seria constituído pelas seguintes lógicas ou princípios: o Estado, segundo a concepção de Thomas Hobbes (obrigação política vertical entre cidadãos e Estado), o mercado, de acordo com a tessitura das teorias de Adam Smith e John Locke (obrigação política horizontal individualista e antagônica entre os parceiros de mercado) e a comunidade rousseauniana (obrigação política horizontal solidária entre membros da comunidade).

O pilar da emancipação, seria constituído pelas três lógicas da racionalidade definidas por Weber: a racionalidade estético-expressiva das artes e literatura, a racionalidade cognitivo instrumental da ciência e da tecnologia e a racionalidade moral-prática da ética e do direito (SANTOS, 2005).

A sustentação do projeto de modernidade residiria no equilíbrio entre os pilares regulatório e emancipatório, atingido às custas de um desenvolvimento harmonioso e recíproco, obtido por meio da completa racionalização da vida coletiva e individual e de suas inter-relações, obtendo assim a compatibilização de valores sociais que, em princípio, poderiam ser tidos como incompatíveis, tais como justiça e autonomia, igualdade e liberdade, solidariedade e identidade. 
A modernidade, desde os seus primórdios até o momento do colapso de seu ideário (após a segunda metade do século XX) passou por diversas transformações ${ }^{5}$, mas manteve intacta a sua espinha dorsal: o triunfo da razão.

\section{O ESTADO MODERNO LIBERAL}

O Estado Moderno pressupõe a nítida separação do espaço social em duas esferas, representativas da distinção entre o público e o privado: o Estado e a sociedade civil. Sob o primado do indivíduo e a consciência da subjetividade, a partir da Revolução Francesa ${ }^{6}$, o Estado, segundo Kant, representa a garantia de liberdade do indivíduo, na medida em que faz-se necessária a sua existência para impor uma ordem coletiva que assegure a máxima liberdade individual e ao mesmo tempo, a máxima responsabilidade individual (BITTAR, 2014).

O próprio Estado não pode atingir ou influenciar a esfera individual dos cidadãos. Ao Estado, portanto, impõem-se limites concretos de atuação. Segundo CHEVALLIER ( 2013, p. $51)$,

A regra é a não intervenção e as atividades sociais são em princípio livres: ao Estado é atribuído um domínio de ação excepcional e residual, cobrindo as tarefas socialmente indispensáveis, mas que ele é o único que pode assumir porque elas dizem respeito à soberania ou à "ordem pública"; no mais, e notadamente em tudo o concernente aos intercâmbios econômicos, ele deve deixar livre curso à iniciativa privada, abstendo-se de toda ação que arriscaria deturpar o funcionamento do mercado.

A modernidade cria, assim, de forma bastante evidente, uma secção entre Estado e sociedade civil, por um recorte simbólico do espaço social, com o objetivo de fixar claros limites à atuação estatal na esfera social. Segundo CHEVALLIER (2013, p. 51), “o Estado

\footnotetext{
5 Boaventura de Sousa Santos subdivide a modernidade em quatro grandes períodos: 1) o período de sua constituição, entre o século XVI e finais do século XVIII, único período que não se vincula ao desenvolvimento do sistema capitalista, assim entendido enquanto modo de produção caracterizado pelas relações entre o capital e o trabalho; 2) o primeiro período (capitalismo liberal), que cobre todo o século XIX; 3) o segundo período (capitalismo organizado), que se inicia no final do século XIX e vai até as primeiras décadas depois da $2^{\mathrm{a}}$ Guerra Mundial; e 4) o terceiro período que se inicia no final da década de sessenta e perdura até os dias de hoje (capitalismo desorganizado) (SANTOS. Boaventura de Sousa. Pela mão de Alice. O social e o político na pósmodernidade. 9a ed. Coimbra: Almedina, 2013.)

6 Antes da Revolução Francesa de 1789, temos a primeira versão do Estado Moderno, qual seja, o Estado Absolutista, cunhado na doutrina de Thomas Hobbes, que concebeu a ideia de soberania, unidade territorial e de poder. Importante também para essa época as ideias de Jean Bodin (soberania) e Nicolau Maquiavel ( separação entre ética e política).
} 
não pode fazer tudo: há limites objetivos à sua ação, que resultam da "natureza das coisas"”. A regra é a intervenção estatal mínima na esfera privada.

O Estado Moderno é, ao mesmo tempo, um Estado mínimo e um Estado máximo. Estado mínimo na medida em que sua ação é considerada como potencialmente limitadora da liberdade individual. De outro lado, é condição essencial para o exercício dessa liberdade (SANTOS, 2013).

\section{O DIREITO MODERNO LIBERAL}

O Estado Moderno só consegue exercer o seu papel de guardião das liberdades individuais, da auto-regulação do mercado e da ordem pública por intermédio do direito. Portanto, o Estado Moderno é necessariamente um Estado de direito. O direito intermedia, assim, as relações entre as diferentes esferas sociais: Estado e sociedade civil. Nas palavras de Ricardo Maurício Freire Soares,

o Estado de Direito sintetiza um duplo e convergente processo de estatização do Direito e jurisdicização do Estado. Esta nova forma de organização estatal inaugura um padrão histórico específico de relacionamento entre o sistema político e a sociedade civil. Esta relação é intermediada por um ordenamento jurídico que delimita os espaços político e societal. A ordem jurídica acaba por separar a esfera pública do setor privado, os atos de império dos atos de gestão, o interesse coletivo das aspirações individuais.

O direito, para exercer o seu papel de interlocutor entre Estado e Sociedade, só poderia ter como fonte criadora primária, no contexto de uma suposta realidade de esferas sociais distintas e com papeis pré-definidos, o próprio Estado, não em sua versão unificada dos tempos do absolutismo, mas subdivido (sem prejuízo de sua soberania) em três poderes distintos e autônomos, segundo a clássica concepção de Montesquieu.

O Estado assim, autolimita-se. Ao Poder Executivo resta a atuação definida nas leis, pautada no primado da liberdade do indivíduo e na garantia dos direitos individuais. O direito administrativo é o direito de exceção ao direito comum (direito privado), tendo como preocupação maior frear o próprio Estado. A função de criar o direito é cometida ao Poder Legislativo, composto pelos representantes da nação burguesa. O Poder Judiciário tem como competência julgar os conflitos, tendo como seu representante o magistrado, "a boca que pronuncia as palavras da lei” (MONTESQUIEU, tradução livre, apud BARROSO, 2001, p. $13)$. 
Todo esse sistema só poderia funcionar de maneira harmônica mediante a edição de uma norma de envergadura constitucional ${ }^{7}$, produto de uma razão imanente e universal, fundamento último da legitimidade do Estado e do Poder, refletida na ordem jurídica. Nela estão consignados a organização estatal e de seus três poderes, a afirmação da soberania estatal e da unidade nacional, os direitos e garantias individuais e os limites do próprio Estado.

$\mathrm{O}$ direito natural que predominou durante o primeiro período da modernidade e impulsionou a Revolução Francesa de 1789, transmuda-se, pois, em direito estatal, que supervaloriza as fontes formais do direito, desconsidera o direito não estatal e se coloca como um sistema autossuficiente e independente, composto por normas que obedecem à uma lógica hierárquica objetivamente definida ${ }^{8}$. Assiste-se, assim, à normatização do direito em sua dimensão subjetiva, direcionada ao indivíduo e ao próprio Estado, que passa a ser considerado sujeito de direitos e deveres.

A modernidade cria, pois, um dos seus mitos mais consolidados: a equivalência entre a lei e o direito, a concepção do direito enquanto norma escrita, institucionalizada. Nas palavras de CHEVALLIER (2013, p. 52), "o Estado de direito descansa na crença profundamente ancorada nas virtudes da dogmática jurídica", assentando-se sobre o "fetichismo da regra", tomando a norma jurídica pela própria realidade, como se a lei fosse capaz de fazer advir o que anuncia, sendo que a sua positivação em um ordenamento fechado, sistêmico e sem lacunas é o que garante a sua confiabilidade enquanto instrumento de pacificação social ${ }^{9}$.

Assim, a lei e os seus comandos, construídos dentro de uma lógica racional objetiva, passam a ser tomados como realidade, verdade absoluta e imponível aos cidadãos e ao próprio

7 A modernidade inaugura a era das constituições escritas. Em 1734, Bolingbroke (Dissertation upon Parties) assim define a Constituição: "aquel conjunto de leyes, instituciones e costumbres, derivadas de ciertos principios inmutables de laa razón y dirigidas a ciertos fines inmutables del bien común, que constituyen el conjunto del sistema según el cual la comunidade ha convenido y aceptado ser gobernada..." (apud FIORAVANTI, Maurizio. Constitución. De la Antigüedad a nuestros días. Madri: Trotta Editorial, 2001, p. 95).

8 Nas palavras de Alessandro Severino Vallér Zenni, “A propósito do jus, considera-se um arsenal de normas jurídicas logicamente concatenadas e hierarquizadas, representando a vontade do contrato social, que, por ficção, decorre da vontade da maioria, merecendo uma interpretação restrita diante dos mitos da certeza e segurança jurídica que procuram encampar via positivação. (in, A Crise do direito liberal na pós-modernidade. Porto Alegre: Sergio Antonio Fabris Editor, 2006.

9 Diogo de Figueiredo Moreira Neto afirma que "a modernidade, por cinco séculos, se caracterizou pela produção do Direito pelo Estado, explicando-se sua prolongada, reconhecida e sacralizada identificação com a legalidade." (MOREIRA NETO. Diogo de Figueiredo Moreira. Poder, Direito e Estado. O Direito Administrativo em tempos de globalização. Belo Horizonte: Fórum, 2011, p. 47). 
Estado, crença essa respaldada por uma ciência jurídica que distorce o conteúdo do direito, na medida em que estabelece ser o direito expressão da vontade coletiva.

O direito moderno é, pois, um direito estatal, positivo e científico, fruto da racionalidade cognitivo-instrumental da ciência moderna, pautada pela segregação entre o sujeito (jurista) e o objeto (normas) e converte-se, assim, em uma racionalidade intrínseca, externada por seus mais relevantes atributos (CHEVALLIER, 2009): a) sistematicidade: o direito se apresenta como um sistema de normas solidárias e hierarquizadas, reunidas entre si por relações lógicas e necessárias; b) generalidade: a realidade social é apreendida pelo direito por meio de conceitos abstratos e as soluções aplicáveis aos casos concretos podem ser deduzidas das regras gerais; c) estabilidade: as normas jurídicas são dotadas de certa permanência, o que confere aos cidadãos a previsibilidade das consequências de seus atos em face da regra que os disciplina.

O monopólio estatal do direito representa a colonização da racionalidade moralprática do direito pelo Estado que, notadamente a partir do século XIX, passa a ser orientado pela supremacia da lógica do mercado, cunhada na máxima "Laissez faire, laissez passer, et le monde va la lui-même". A teoria política denomina o Estado cunhado nesse contexto de Estado Liberal.

No século XIX, o isoformismo entre direito, Estado e ciência, que tem como substrato comum a observância aos interesses do mercado, acentua-se em virtude da filosofia que os informa, o positivismo. Nos dizeres de Luís Roberto Barroso (2001, p. 21),

O positivismo filosófico foi fruto de uma idealização do conhecimento científico, uma crença romântica e onipotente de que os múltiplos domínios da indagação e da atividade intelectual pudessem ser regidos por leis naturais, invariáveis, independentes da vontade e da ação humana.

As teses fundamentais do positivismo filosófico são assim sintetizadas por BARROSO ( 2001, p. 21):

(i) a ciência é o único conhecimento verdadeiro, depurado de indagações teológicas ou metafísicas, que especulam acerca de causas e princípios abstratos, insuscetíveis de demonstração; (ii) o conhecimento científico é objetivo. Funda-se na distinção entre sujeito e objeto no método descritivo, para que seja preservado de opiniões, preferências ou preconceitos; (iii) o método científico empregado nas ciências naturais, baseado na observação e na experimentação, deve ser estendido a todos os campos de conhecimento, inclusive às ciências sociais.

O positivismo significa, em suma, a ordenação do caos natural e social, estabelecida de maneira regular através de um conhecimento sistemático, de forma a garantir a certeza, a 
previsibilidade e o controle (SANTOS, 2005). Sob o ponto de vista social, o positivismo estabelece a ordem social para que a sociedade seja controlada, tornando-se previsível e certa.

A ciência jurídica positivista traduziu-se na pretensão de apartar do direito a moral e os valores transcendentais. O direito positivo, é pois, norma, ato emanado do Estado com caráter imperativo e de natureza coercitiva. BARROSO (2001, p. 22) aponta como características essenciais do positivismo jurídico:

(i) a aproximação quase plena entre Direito e norma; (ii) a afirmação da estatalidade do Direito: a ordem jurídica é una e emana do Estado; (iii) a completude do ordenamento jurídico, que contém conceitos e instrumentos suficientes e adequados para solução de qualquer caso, inexistindo lacunas; (iv) o formalismo: a validade da norma decorre do procedimento seguido para a sua criação, independendo do conteúdo.

O positivismo conferiu ao direito o status de instrumento de dominação racional, legitimado "pelo sistema racional de leis universais e abstractas, emanadas do Estado, que presidem a uma administração burocratizada e profissional, e que são aplicadas a toda a sociedade, por um tipo de justiça baseado numa racionalidade lógico-formal.” (SANTOS, 2005, p. 142).

O direito positivo é assim "codificador da unidade massificadora de comportamentos sociais, que deveriam se estandarlizar em uniformidades favoráveis ao desenvolvimento do controle normalizador" (BITTAR, 2014, p. 52). Sob essa ótica, mostra-se necessária a sistematização do direito em códigos, com regras textualmente garantidas e exegeticamente controladas. Assiste-se, pois, à privatização da sociedade civil e o direito privado, a partir das codificações de natureza civilista (Jürgen Habermas, 2014).

\section{A REINVENÇÃO DO ESTADO E DO DIREITO MODERNOS: O ESTADO-} PROVIDÊNCIA E A NOVA FACE DO DIREITO

Paralelamente à ascensão do positivismo científico e jurídico, a expansão imperialista estatal, o desenvolvimento de técnicas de produção industrial em escala e o consequente processo de urbanização da sociedade, com o surgimento de áreas densamente povoadas sob condições precárias de vida, trouxeram à tona a contraditoriedade implícita ao projeto da modernidade em sua feição liberal.

Em verdade, as contradições da modernidade há um tempo já se anunciavam, Relatanos Zygmunt Bauman ( 2010, p. 158) que: 
... perto do fim do século XIX, a Era Moderna parecia, aos olhos de muitos, uma benção confusa. Uma grande realização da humanidade, sem dúvida, mas a que preço; um preço alto demais, talvez. Ficava cada vez mais claro para a elite educada que o esperado reino da Razão se materializava muito devagar. Mais importante, já não estava claro se um dia poderia se materializar.

O Estado teve assim que se reinventar para se adaptar às transformações sociais que ele mesmo catalisara. Era preciso alterar as condições sociais de vida para manter acesa a crença nas promessas da modernidade ${ }^{10}$. O Estado passou então a ampliar as suas relações com a comunidade ${ }^{11}$, deslocando, assim, a linha de demarcação que dividiam as esferas pública e privada.

Tal deslocamento ocorreu por meio da positivação de direitos sociais, da extensão do direito de voto, da implementação de políticas sociais distributivas e da inserção do Estado em questões antes afetas apenas aos interesses particulares, como a intervenção na economia. Surge então o Estado-Providência (Welfare State), no período cunhado por SANTOS (2005, 2013) como capitalismo organizado.

A crescente intervenção do Estado na sociedade provocou um crescimento do direito e da ordem por ele regulada, em consequência do incremento do aparelhamento estatal, necessário para que o Estado pudesse cumprir a contato o seu novo papel. Surgem novos ramos do direito (direito econômico, direito do trabalho), que apresentam como ponto comum a mescla de elementos de direito público e de direito privado, ratificando o deslocamento dos limites inicialmente estabelecidos pelo Estado entre a esfera pública e a esfera privada.

O direito, enquanto produto da ordem estatal, acompanha essa transformação, reveste-se de um caráter material e regulador, sem contudo, abrir mão de sua positividade. Diante dessa nova interdependência entre as esferas estatal e social, observa-se o rompimento do sistema do direito privado clássico. Ilustrando tal assertiva, HABERMAS (2014, p. 339) esclarece: "Na sociedade industrial constituída pelo Estado de bem-estar social, multiplicamse condições e relações que não podem mais ser classificadas pelos institutos do direito

10 Para SANTOS (2005), o segundo período da modernidade, marcado pelo positivismo, começou por distinguir as promessas que podiam e as que não podiam ser cumpridas em uma sociedade capitalista dinâmica. Em seguida, concentrou-se nas promessas passíveis de cumprimento e tentou, através da socialização e da influenciação cultural, eliminar as promessas irrealizáveis, buscando forjar a inexistência de qualquer "défice". Nos dizeres do autor (2005, fls. 149), "Solidariedade, justiça e igualdade podiam ser compatíveis com autonomia, identidade e liberdade, desde que cada conjunto de valores, aparentemente incompatíveis, fosse reduzido ao que realisticamente exequível numa sociedade capitalista."

11 Importante consignar que o ressurgimento de práticas que a princípio poderiam ser intituladas de práticas comunitárias assim não podem ser consideradas, já que ocorreram sob a égide do Estado-Providência e como parte integrante da ampliação da esfera estatal. (SANTOS, 2005). 
privado nem do direito público. Ao contrário, forçam a introdução das chamadas normas de direito social".

Ainda na seara jurídica, a proximidade entre Estado e sociedade alterou a dinâmica do direito constitucional e do direito administrativo. As constituições (a pioneira foi a Constituição Mexicana de 1917, seguida pela Constituição de Weimar, de 1919) passaram a reconhecer os direitos sociais e econômicos.

O constitucionalismo social, que marca as nuances do novo EstadoProvidência, continuou, nas palavras de Miguel Calmon Dantas, "com a penhorada crença na racionalidade, bondade e legitimidade do legislador, apresentando-se, também, como Estado legal" (2009, p. 172). Contudo, essa legalidade cede à hipertrofia do Poder Executivo, já que espera-se agora que o Estado seja capaz de, através de sua intervenção na esfera privada e atuando na implementação de políticas públicas e na prestação de serviços públicos, promover a justiça social.

A maior concretude do direito administrativo enquanto direito do Estado é oriunda do já mencionado alargamento das funções estatais em nome da consecução do bemestar geral, sem prejuízo da manutenção dos interesses do mercado. O Estado passa a ser protagonista no atendimento de uma gama de necessidades sociais outrora buscadas individualmente dentro da esfera privada e que passam a compor o rol de direitos sociais positivados no ordenamento jurídico estatal.

O Estado-Providência passa a agir como mediador da vida social. O espaço privado sociedade civil se contamina pela atuação estatal exacerbada. O Estado passa a ser o tutor da sociedade: é, ao mesmo tempo, o garantidor do desenvolvimento coletivo e o protetor de cada indivíduo.

O entrelaçamento entre o público e o privado nessa fase representa, para HABERMAS (2014), a dialética de socialização do Estado e da estatização da sociedade e acaba por destruir, assim, a base da esfera pública burguesa - a separação entre Estado e sociedade.

A subsunção da esfera privada pela intervenção estatal mediante a positivação de direitos sociais denota que o relacionamento do Estado-Providência com a sociedade-cliente continua a ser a lei e seus mecanismos burocráticos autoritários embora agora acompanhada por regulamentos de outras esferas governamentais. Permanece, todavia, a atuação legislativa lapidada pela Teoria Pura do Direito kelseniana, que, paradoxalmente, afasta mais ainda os 
cidadãos da esfera pública, ao exigir-lhes subserviência em detrimento de mobilização ativa. Emerge nesse período a pseudo-verdade da supremacia do Estado sobre a sociedade.

O fetichismo jurídico e institucional provocado pelo aumento da esfera pública na sociedade teve como consequência mais severa a banalização do direito, transformado em instrumento de legitimação do Estado, ao invés de fonte de legitimação do Estado. Ilustra tal afirmativa a lição de J. P. Henry (apud Chevallier, 2013, p. 82): "Paralela e justamente quando as suas ambições se desenvolvem, assistimos a uma perda de eficácia do direito. A inflação normativa acarreta de fato um fenômeno de desvalorização do direito e o impede de preencher de maneira satisfatória a função reguladora que lhe incumbe".

O legalismo exacerbado leva, por sua vez, ao crescimento do espírito burocrático, na medida em que a burocracia “é a máxima expressão da literralidade das regras, dos procedimentos e da instabilidade das instituições do Estado" (BITTAR, 2014, p. 46)

Por volta da década de 60 fica evidente que o Estado-Providência entra em crise, por não ter conseguido assegurar uma distribuição mais justa dos benefícios sociais e um sistema politico estável e democrático. A lógica do mercado avança mais ainda sobre as demais lógicas regulatórias e sobre as lógicas emancipatórias e inaugura o período denominado por SANTOS de capitalismo desorganizado, descortinando a crise dos paradigmas da modernidade.

\section{MODERNIDADE EM CRISE E SEUS REFLEXOS NO DIREITO MODERNO}

O terceiro período da modernidade (capitalismo desorganizado), que perdura até os dias atuais, demonstrou e continua a desvelar as fragilidades das crenças da modernidade, a sua incapacidade de manter algumas conquistas e a impossibilidade de cumprir promessas inacabadas, além de externar os déficits ocultados pelo Estado-Providência.

A racionalidade instrumental que mediou as relações entres os pilares de regulação e emancipação da modernidade acabou por provocar um desequilíbrio em favor do mercado, que extravasou a seara econômica em direção às demais lógicas e princípios, atingindo uma pujança sem precedentes, com a colonização em grande escala do princípio do Estado e da comunidade.

Com efeito, nas palavras de SOARES

O programa da modernidade dissolveu-se num processo de racionalização da sociedade, que acabou por vincular a razão às exigências do poder político e à lógica 
específica do desenvolvimento capitalista. O conhecimento científico da realidade natural e social, entendido como meio de emancipação do ser humano, é submetido às injunções do poder vigente.

Denuncia-se o entrelaçamento das formações discursivas com as relações de poder. Com o aparecimento de uma razão tecnocrática, o saber se torna o serviçal e corolário lógico do poder. O discurso, mormente o científico, é convertido num eficiente instrumento de domínio. O discurso não é mais simplesmente aquilo que traduz as lutas ou os sistemas de dominação, mas aquilo pelo que se luta, o poder de que todos querem se apoderar.

Sendo assim, a razão de matriz iluminista se banalizou, restringindo seu horizonte e delimitando seu campo de indagação aos interesses do poder. Favoreceu o progresso técnico e o crescimento econômico, mas engendrou problemas sociais. A racionalidade moderna não mais atendeu às exigências originárias do homem ( liberdade, justiça, verdade e felicidade), mas, do contrário, sucumbiu às exigências do mercado.

Quanto ao Estado, este parece ter perdido a capacidade de regular o mercado em nível nacional, a figura do Estado-nação começa a perder espaço no cenário global e a sua responsabilidade na produção de bem-estar social começa a ser reduzida paulatinamente.

Não obstante se assista à redução do papel social do Estado, não se observa a redução do peso da burocracia estatal, o que contribui para a ineficácia da administração pública e para um "crescente autoritarismo de um sem-número de burocracias desajustadas, cada uma exercendo o seu micro-despotismo sobre cidadãos cada vez mais impotentes e politicamente incapazes" (SANTOS, 2005, p. 155).

A partir da constatação da subversão da racionalidade instrumental aos interesses econômicos, os ideais positivistas de neutralidade, certeza e separação entre sujeito-objeto restam superados.

O pensamento segundo o qual existiria apenas uma única explicação verdadeira para os fenômenos naturais e sociais foi uma construção da modernidade ocidental que sucumbiu aos seus próprios excessos. O progresso, o bem-estar, o conhecimento e a liberdade terminaram por não se realizar. No lugar dessas promessas, a modernidade legou à humanidade a alienação, o niilismo e a reificação do ser humano e da própria realidade.

A crise da modernidade trouxe à lume a insuficiência dos seus mecanismos de gestão de conflitos e de ajustamento estrutural para resolver as anomalias surgidas de suas próprias contradições internas.

Maria Tereza Fonseca Dias (2003, p. 32) esclarece que

"A crise do direito moderno relaciona-se com a crise do paradigma do direito materializado do Estado social (ou Estado de bem-estar social), de forma que o sistema de crenças da modernidade aos poucos vais desaparecendo, ou, ao menos, vai sendo pulverizado e imiscuído a outros valores". 
Uma das condições essenciais à racionalidade do direito moderno era a estabilidade das normas e dos fatos. Entretanto, conforme assinala SANTOS ( 2005, p. 152)

O desgaste desta condição era inevitável perante o dinamismo das sociedades capitalistas neste século $[\mathrm{XX}]$ e perante o papel central que o Estado nele desempenhou. Com o progressivo envolvimento do Estado nos processos económicos e sociais e à medida que este vai se tornando mais complexo, diferenciado e sistémico, o direito abstracto, formal e universal, recua perante o direito contextualizado, particularista e circunstancial.

A crise do direito moderno decorre da redução histórica de sua autonomia e da sua eficácia à autonomia e à eficácia do próprio Estado. O fato de o direito não ser autônomo em relação à própria estrutura estatal, condição esta já presente no Estado Liberal e reforçada no Estado-Providência, leva a problemas operacionais recorrentes, tais como a demora dos processos, altos custos da justiça e o congestionamento dos tribunais. Tais problemas são gerados pelo excesso de juridicização (interiorização do mundo exterior feita pelo direito) e pela ineficácia do direito, oriunda da discrepância entre a sua lógica interna e a lógica das outras esferas da vida social por ele reguladas (SANTOS, 2005).

A juridicização do mundo social durante o Estado Providência revela-se como colonização da sociedade pelo direito (Jürgen Habermas, 2012), provocando a desintegração social. Ao mesmo tempo, ao expandir e aprofundar a sua autoridade reguladora sobre a sociedade, "o direito fica "prisioneiro" da política ou dos subsistemas regulados [...] acabando por submeter a uma tensão excessiva a autoprodução dos seus elementos normativos" (Teubner, 1986, p, 311, apud SANTOS, 2005, P. 158), o que redunda em sua ineficácia.

A liberdade individual, garantida apenas a pequena parcela da população que detinha o poder econômico na fase liberal, sucumbirá de maneira inequívoca à nova configuração do Estado moderno durante a sua segunda fase:

O normativismo se torna a "arma cortante das mesmas maiorias a que se havia querido ligar por correntes de papel"; o Estado de Direito tende assim a minar seus próprios fundamentos, a degenerar em seu oposto, em nome dos próprios princípios sobre os quais repousa: de garantidor supremo da liberdade ele se transforma em arma do "poder absoluto (SANTOS, 2005, p. 157).

Em suma, SANTOS (2005) resume as deficiências do direito moderno em três fatores: a ineficácia (aquilo que o direito transforma ou deixa de transformar no mundo exterior), a materialização/juridicização (produto do discurso jurídico científico) e a colonização do mundo da vida, com a eliminação da tensão entre regulação e emancipação. 
Os fatores acima apontados por SANTOS levam à perda dos atributos de sistematicidade, generalidade e estabilidade que caracterizavam o direito racional dos primórdios da modernidade.

A proliferação anárquica de regras, (juridicização) torna demasiadamente confusos os contornos do ordenamento jurídico, colocando em cheque a sua coesão e estabilidade. Segundo CHEVALLIER, (2009, p. 121),

a existência de "hierarquias entrelaçadas", de "objetos jurídicos não identificados", de competências concorrentes testemunham uma nova desordem. Enquanto a hierarquia clássica das normas foi colocada em dúvida em virtude do fato do declínio da lei, da explosão de regulamentos, transformados na era do EstadoProvidência na fonte essencial de obrigações e coerções para os administrados, tal como pela ampliação do poderio do poder jurisdicional, notadamente no nível constitucional, algumas novas normas, de origem exterior, vieram se integrar à ordem jurídica estatal, em condições que permanecem complexas;[...]

As regras, de gerais e abstratas, passam a ser pontuais e especiais, dotadas de conteúdo técnico, circunscritas a determinado tempo e espaço, faltando-lhes, assim o atributo da universalidade, o que faz com que sejam necessários constantes ajustes e alterações, condenando-as à rápida obsolência e perda de vigência. Não se faz mais possível o controle do sentido da lei por intermédio de codificações ou por interpretações oriundas da ciência dogmática do direito.

Por outro lado, a origem estatal e o suposto matiz democrático do direito não se mostram mais suficientes para comprovar a sua legitimidade. A racionalidade do direito não é mais presumida, pois depende de ter a sua eficiência comprovada para ver reconhecida a sua legitimidade $^{12}$. A velha mística da lei enquanto expressão da vontade geral perde credibilidade em face de uma concepção mais realista e crítica sobre a democracia representativa.

Também o individualismo que se constituiu como pedra fundamental do direito moderno passa a ser objeto de duras críticas ( processo este iniciado com a materialização do direito durante o Estado-Providência) e o direito passa a encontrar as suas raízes no grupo social, com o desenvolvimento dos direitos sociais. Paradoxalmente, o direito se enfraquece, pois, conforme metáfora de CHEVALLIER (2009, p. 124), "tudo se passa como se ele tive se tornado, na era do Estado-Providência, um gigante com os pés de barro; o direito está por

12 A condição inicial ideal para o eficaz funcionamento do direito enquanto direito de Estado era a unidade do Estado e a sua separação inequívoca da sociedade civil (sob o ponto de vista da racionalidade instrumental). A juridicização da prática social no Estado-Providência acabou por descaracterizar o caráter estatal exclusivo do direito, razão pela qual, segundo SANTOS (2005), à medida que o direito se entranhava nas práticas sociais que pretendia regular, ou constituir, distanciava-se do Estado, o que justificaria assim, na visão de CHEVALLIER ( 2009), a necessidade de sua legitimação. 
tudo, mas também muito mais vulnerável. Bastará que o Estado-Providência entre em crise para que uma dúvida se instale nos aspectos positivos desse novo direito ${ }^{13}$."

A crise do Estado Providência veio, assim, desconstruir os paradigmas erigidos pelo positivismo jurídico da modernidade.

\section{PERSPECTIVAS PARA O ESTADO E O DIREITO NA PÓS MODERNIDADE}

Após a falência do Estado-Providência, chegamos ao terceiro período, o capitalismo desorganizado $^{14}$, de acordo com a tipologia cunhada por SANTOS $(2005,2009)$, por volta dos $\operatorname{anos} \operatorname{sessenta}^{15}$ e que se estende até os nossos dias. Alerta-nos o referido autor sobre a dificuldade de se analisar esse período, não somente por ainda está a decorrer, como também por sua inegável complexidade.

Utilizaremos aqui a ideia de $\operatorname{BAUMAN}(2009,2010){ }^{16}$ de que, não obstante pretenda-se que a pós modernidade refira-se a algo diferente da modernidade, de que hoje estamos a ingressar em outra forma de viver, não se pode olvidar que esta "nova" forma de viver ainda não encontra-se adequadamente descortinada, eis que imantada em diversos matizes da própria modernidade. Em suma, a pós-modernidade é a modernidade despida de suas ilusões, a consequência de suas promessas não cumpridas.

Nesse sentido, a lição de Ricardo Dip ( 2016, p. 35):

Es bien conocida la controversia en torno a la caracterización de la posmodernidad. Aquí, no obstante, se adopta esa designación al modo de un resultado, no de un camino o un método. La posmodernidad es, por definición, un ente in fieri; no es, sin embargo, un método para desarticular el modernismo y gestar un nuevo tiempo histórico; antes, lo posmoderno ya es ese tiempo supuesto - o tal vez, incluso, algo fuera del tiempo -, el agotamiento coherente y extremo de lo moderno ( Daniel Bell, LIPOVETSKY), el fin de la Historia.

13 Conforme relata CHEVALLIER (2009), o movimento de desregulação que se desenvolverá a partir do fim dos anos 1970 é um indicativo dessa perda de confiabilidade do direito, ao evidenciar que o direito pode ser considerado um entrave ao progresso da economia e da sociedade.

14 Para SANTOS (2005), apesar da expressão que ele utiliza para designar o hodierno modo de produção capitalista, este estaria hoje mais organizado do que nunca. Nos seus dizeres: "A expressão capitalismo desorganizado significa, em primeiro lugar, que as formas de organização típicas do segundo período estão a ser gradualmente desmanteladas ou reconstituídas num nível de coerência muito mais baixo, e, em segundo lugar, que, precisamente por esse processo estar a decorrer, é muito mais visível a demolição das antigas formas organizativas do que o perfil das novas formas que irão substitui-las" (p. 153).

15 Para Jean-François Lyotard, que inaugurou as discussões sobre a pós-modernidade, a partir da crítica às metanarrativas modernas, a pós-modernidade começou desde pelo menos do final dos anos 50 (2013). Em verdade, não existe consenso sobre qual data marcaria o início da pós-modernidade.

16 Em posição dissonante citamos Habermas, para quem a modernidade não é um projeto falido, mas um projeto incompleto, a ser finalizado através de uma nova racionalidade: a racionalidade comunicativa. 
SANTOS (2005) denomina esses períodos transicionais como "transições paradigmáticas” e assim os explica: “ Tais transições ocorrem quando as contradições internas do paradigma dominante não podem ser geridas através dos mecanismos de gestão de conflitos e de ajustamento estrutural desenvolvidos pelo paradigma em causa" (p. 167). Esse momento assim é definido por SANTOS (2005, p. 41):

Há um desassossego no ar. Temos a sensação de estar na orla do tempo, entre um
presente quase a terminar e um futuro que ainda não nasceu. O desassossego resulta
de uma experiência paradoxal: a vivência simultânea de excessos de determinismo e
de excessos de indeterminismos. [...] A coexistência destes excessos confere ao
nosso tempo um perfil especial, um tempo caótico onde ordem e desordem se
misturam em combinações turbulentas.

O desencanto provocado pela consciência da falência das promessas e anseios da modernidade, aliado ao desassossego provocado pela percepção de uma nova realidade que ainda não se consumou por completo, é a pura constatação de uma situação de vida que abarca o mundo enquanto aldeia global única e, ao mesmo tempo, tão diversa. É inegável que estamos a presenciar o desenvolvimento de "um novo modelo de organização dos pensamentos e de atitudes humanas que atua e reflete nas organizações sociais, políticas e econômicas, alterando as bases em que estas se fundam" ( VIEGAS, 2014, p. 41).

Ao contrário da modernidade pautada pelo eterno, imutável, absoluto, verdadeiro, racional, uno, vertical, dedutível, científico, comprovável, provado, ordenado e regulado, descortina-se o contexto pós-moderno, que é transitório, mutável, relativo, provável, sensível, múltiplo, horizontal, indutível, pragmático, estimável (BITTAR, 2014).

Nesse contexto, o Estado nacional se desfacela em âmbito internacional com a nova organização mundial pautada na globalização, com a supressão das fronteiras nacionais em termos de mercado, trânsito de pessoas e culturas.

Conforme bem salientado por SANTOS (2005), a degradação do desempenho social do Estado fê-lo perder o estatuto de locus privilegiado de análise e de prática social, reduzindo assim a sua participação e responsabilidade na produção do bem estar social, mantendo, contudo o peso da burocracia a produzir a ineficácia da administração púbica.

A perda de confiança da sociedade na capacidade do Estado de resolver as suas mazelas traduz-se na privatização das políticas sociais, em um novo protagonismo da comunidade na esfera pública. 
A desestadualização, enquanto necessário corolário dos novos conceitos informadores do direito pós-moderno (ROCHA, 2013, p. 222) reflete a reconstrução de outro modelo estatal, no qual a sociedade é que deve organizar o direito e não o contrário. Nesse sentido, esclarece FIGUEIRAS (2013, p. 84) que

O Direito começa a ser produto da ação de vários atores sociais, primeiro, num plano supra-estadual, resultante da globalização e, segundo, num plano infraestadual, em resultado do aumento dos mecanismos de autorregulação. As ideias que lhe estão subjacentes são as da liberação dos vários setores da vida de uma regulamentação racional, o acolhimento de regras extralegais e de equivalentes funcionais do Direito e a transformação do Direito racional num Direito reflexivo.

Ainda nos dizeres de FIGUEIRAS (2013, p. 87), “A comunidade vai tomando conta de si, não restando outra alternativa ao Estado que retirar-se lenta e progressivamente, limitando-se a ser um mero órgão central fiscalizador."

Em um contexto de redução gradual do papel estatal (é o direito em busca de sua autonomia), a inversão de direção na relação direito-sociedade, sinalizada em FIGUEIRAS (2013) justifica-se pela necessidade de o Estado se valer do auxílio da sociedade para realizar as suas funções. A entrada da sociedade como co-autora das realizações estatais revela-se no seu papel de intérprete dos direitos previstos constitucionalmente (HÄBERLE, 2002) e no seu protagonismo no processo discursivo de legitimação do direito (HABERMAS, 2003, v. I, p. 309).

A redução gradual do papel estatal na dinâmica social faz com que o Estado recorra ao auxílio da própria sociedade para "cumprir a sua missão de forma eficiente, proporcionando o melhor atendimento possível das necessidades e interesses da coletividade" (BATISTA JÚNIOR, 2007, p.15).

A racionalidade instrumental cede espaço à racionalidade discursiva, que já não aceita a separação sujeito/objeto. No campo da epistemologia jurídica, a hermenêutica ganha destaque. Segundo SOARES,

o direito pós-moderno é relativo. Isto porque não se pode conceber verdades jurídicas absolutas, mas sempre dados relativos e provisórios. Na pós-modernidade jurídica, marcada pela constelação de valores e pelos fundamentos linguísticos, qualquer assertiva desponta como uma forma de interpretação. O relativismo pósmoderno oprotuniza a consolidação de um saber hermenêutico.

O direito pós-moderno caracteriza-se, pois, pela complexidade dos seus mecanismos de produção e formas de articulação das normas jurídicas. A flexibilidade normativa se justifica pela necessidade de o direito adaptar-se à evolução da realidade e às novas situações (DIAS, 2003). O direito pós-moderno passa a enfatizar o estabelecimento das condições de 
decidibilidade dos conflitos por meio de técnicas persuasivas e consensuais. Sob este paradigma, o direito que, na modernidade, foi alçado à condição de racionalizador da ordem social (FIGUEIRAS, 2013, p. 83), passa por profundas transformações conceituais.

A velocidade e a diversidade dos acontecimentos em uma sociedade pós-moderna e a sensação de fugacidade própria dos atuais tempos convidam o direito a retornar à sua dimensão ética e axiológica, sob o primado de teorias pós-positivistas, comunitárias, discursivas e pluralistas, nas quais se examina a dimensão do direito para além da legalidade positivada e da legitimidade autoritária, atingindo também aspectos morais e a inserção de princípios no sistema jurídico, sob a ótica de uma nova hermenêutica submetida à teoria dos direitos fundamentais.

\section{CONCLUSÃO}

Quando as anomalias verificadas na realidade não conseguem ser solucionadas pelas respostas fornecidas pelo paradigma vigente, faz-se necessário colocar outras lentes para que, a partir de outro ponto de vista, seja possível enxergar as possíveis respostas para os problemas que se apresentam.

O Estado e o direito modernos, cunhados sob o pálio da racionalidade instrumental e cientificidade positivista, não obstante tenham se reinventado ao longo de sua existência, não lograram produzir o bem-estar, a felicidade e a garantia de direitos mínimos à grande parcela da humanidade.

A crise desses modelos incita-nos a seguir a lição de Thomas Kuhn (2013, p.158): "O significado de crises consiste exatamente no fato de que indicam que é chegada a ocasião para renovar os instrumentos".

O momento pós-moderno ainda está por se definir e dessa indefinição decorre a incerteza dos tempos atuais. O Estado de direito democrático reclama o abandono das "falsas soluções, mil e uma vezes tentadas, que nos deixam sempre no mesmo lugar" (VILLALOBOS, 2013, p. 374) para buscar soluções compatíves com as características das relações sociedade-Estado da atualidade.

\section{REFERÊNCIAS}


BARROSO. Luís Roberto. Fundamentos teóricos e filosóficos do novo direito constitucional brasileiro (Pós-modernidade, teoria crítica e pós-positivismo). Revista de Direito Administrativo. Rio de Janeiro, n. 225, jul./set. 2001, p. 5-37.

BATISTA JÚNIOR. Onofre Alves. Transações administrativas. Rio de Janeiro: Quartier Latin, 2007.

BAUMAN, Zygmunt. Legisladores e Intérpretes. Trad. Renato Aguiar. Rio de Janeiro: Zahar, 2010.

Zahar, 2010.

Vida líquida. Trad. Carlos Alberto Medeiros. $2^{\mathrm{a}}$ ed. Rio de Janeiro:

BITTAR, Eduardo C. B.; ALMEIDA, Guilherme Assis de. Curso de Filosofia do Direito. $11^{\text {a }}$ ed. São Paulo: Atlas, 2015.

BITTAR, Carlos C. B. O Direito na Pós-Modernidade. $3^{\text {a }}$ ed. São Paulo: Atlas, 2014.

CHEVALIER, Jacques. O Estado Pós-Moderno. Trad. Marçal Justen Filho. Belo Horizonte: Fórum, 2009.

. O Estado de Direito. Trad. Antonio Araldo Ferraz Dal Pozzo e Augusto Neves Dal Pozzo. Belo Horizonte: Fórum, 2013.

DANTAS, Miguel Calmon. Constitucionalismo dirigente e pós-modernidade. Rio de Janeiro: Saraiva, 2009.

DIAS, Maria Tereza Fonseca. Direito Administrativo Pós-Moderno. Belo Horizonte: Mandamentos, 2003.

DIP, Ricardo. Seguridad jurídica y crisis del mundo posmoderno. Madrid: Marcial Pons, 2016.

FIGUEIRAS. Cláudia Sofia Melo. Arbitragem: a descoberta de um novo paradigma de justiça tributária? In: FONSECA. Isabel Celeste M. (Coord). A Arbitragem Administrativa e Tributária - Problemas e Desafios. Coimbra: Almedina, 2013, p. 81-102.

FIORAVANTI, Maurizio. Constitución. De la Antigüedad a nuestros días. Madri: Trotta Editorial, 2001.

FOUCAULT, Michel. Ditos e escritos II: arqueologia das ciências e história dos sistemas de pensamento. Rio de Janeiro: Forense Universitária 2000.

HÄBERLE, Peter. Hermenêutica Constitucional. A sociedade aberta dos intérpretes da Constituição: contribuição para a interpretação pluralista e " procedimental" da Constituição. Trad. Gilmar Ferreira Mendes. Porto Alegre: Sergio Antonio Fabris Editor, 2002. 
HABERMAS, Jürgen. Teoria do agir comunicativo. Racionalidade da ação e racionalização social. V. 1. Trad. Paulo Astor Soethe. São Paulo: Martins Fontes, 2012.

Direito e Democracia: entre facticidade e validade. Tomo I. Trad.

Flavio Beno Siebeneichler. Rio de Janeiro: Tempo Brasileiro, 2003.

São Paulo: Editora Unesp, 2014.

Mudança estrutural da esfera pública. Trad. Denilson Luís Werle.

KUHN, Thomas. A estrutura das revoluções científicas. Trad. Beatriz Vianna Boeira e Nelson Boeira. 12ª ed. Coleção Debates. Ciência. São Paulo: Perspectiva, 2013.

LYOTARD. Jean-François. A condição pós-moderna. Trad. Ricardo Corrêa Barbosa. $15^{\mathrm{a}}$ ed. Rio de Janeiro: José Olympio, 2013.

MOREIRA NETO, Diogo de Figueiredo Moreira. Poder Direito e Estado. O Direito Administrativo em tempos de globalização. Belo Horizonte: Fórum, 2011.

ROCHA. Joaquim Freitas da. A desestadualização do direito tributário. Em particular, a privatização do procedimento e a arbitragem. In: FONSECA. Isabel Celeste M. (Coord). A Arbitragem Administrativa e Tributária - Problemas e Desafios. Coimbra: Almedina, 2013, p. 221-225.

SANTOS, Boaventura de Souza. A crítica da razão indolente: contra o desperdício da experiência. V. 1: Para um novo senso comum: a ciência, o direito e a política na transição paradigmática. $5^{\text {a }}$ ed. São Paulo: Cortez, 2005.

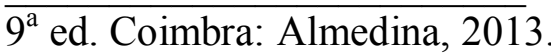

Pela mão de Alice. O social e o político na pós-modernidade.

SOARES, Ricardo Maurício Freire. Elementos para uma cultura jurídica pós-moderna.

Disponível em: http://portaldireitospordireito.blogspot.com.br/2011/03/ricardo-mauriciofreire-soares-cultura.html. Acesso em: 18/05/2017.

VIEGAS, Carlos Athayde Valadares. Legitimidade democrática da jurisdição constitucional: cidadania e pós-modernidade. Belo Horizonte: D’Plácido Editora, 2014.

VILLA-LOBOS. Nuno. Novas configurações da Justiça Administrativa e Fiscal em Portugal. In: FONSECA. Isabel Celeste M. (Coord). A Arbitragem Administrativa e Tributária - Problemas e Desafios. Coimbra: Almedina, 2013, p. 363-374.

ZENNI, Alessandro Severino Vallér. A Crise do direito liberal na pós-modernidade. Porto Alegre: Sergio Antonio Fabris Editor, 2006. 